\title{
Um Estudo dos Princípios Aditivo e Multiplicativo por meio de Jogos
}

\author{
A Study on the Additive and Multiplicative Principles by means of Games
}

\author{
Francisca Brum Tolio e Eleni Bisognin \\ Centro Universitário Franciscano \\ francisca.tolio@iffarroupilha.edu.br; eleni@unifra.br
}

\begin{abstract}
Resumo
Neste artigo são relatados resultados parciais de uma pesquisa realizada num curso de Mestrado Profissional em Ensino de Física e Matemática, tendo como propósito investigar as contribuições que a Metodologia da Resolução de Problemas e a utilização de jogos e materiais manipuláveis podem propiciar para o ensino e aprendizagem do Principio Aditivo e Principio Multiplicativo. Foram participantes da pesquisa alunos de uma turma da $3^{a}$ série do Ensino Médio. No referencial bibliográfico é abordada a resolução de problemas e é apresentado um breve histórico da Análise Combinatória. Os dados da pesquisa foram coletados por meio dos registros escritos dos alunos, das observações anotadas no diário de campo da professora e por meio de gravações em áudio. Da análise feita, verificou-se que o desempenho dos alunos em buscar estratégias de resolução foi deficitário, porém, observou-se também que os alunos foram capazes de construir os conceitos relacionados aos conteúdos abordados de tal forma a diferenciar os princípios estudados e, na maioria das vezes, realizando a aplicação correta do conteúdo abordado.
\end{abstract}

Palavras-chave: Resolução de Problemas; Princípio Aditivo e Multiplicativo; Jogos.

\begin{abstract}
In this article the partial results of a research accomplished in a Professional Master Course in the teaching of Physics and Mathematics are reported, aiming to investigate the contributions of the Problem Solving Methodology if the use of games and handling materials can provide to the teaching and learning processes of the Additive and Multiplicative Principles. The participants of this research were students from a third year group of high school. In the bibliographic referential, the problem solving methodology is approached and a brief report of Combinatorial Analysis is presented. The research data were collected by the use of the students' written notes, the observations done in the teacher's field diary and by audio recordings. From the analysis done, it was verified that the students' performance in looking for solving strategies presented difficulties, however, it was also noticed that the students were able to create new concepts related to the contents given in a way to differentiate the principles studied and, most of the times, doing the correct use of the content
\end{abstract}

Keywords: Problems Solving, Additive and Multiplicative Principles, Games 


\section{Introdução}

A Matemática, muitas vezes, é vista pelos alunos como uma disciplina difícil, pois em alguns momentos se faz necessário a compreensão de conceitos matemáticos mais abstratos e isso pode dificultar a aprendizagem. Trabalhar essa disciplina é um desafio para nós professores, que devemos planejar aulas interessantes, motivadoras e mostrar a utilidade dos conteúdos matemáticos aos nossos alunos.

Muitas vezes, no Ensino Médio, é comum observarmos um ensino meramente estanque, sem interação com a realidade do aluno, ou ainda, sem a interação com as demais disciplinas. Esse modo de ensinar torna as aulas pouco aprazíveis, pois os alunos não veem a empregabilidade dos conceitos matemáticos, apreendendo somente fórmulas e processos mecânicos de resolução de exercícios, dificultando a interpretação e a interação.

A Análise Combinatória é um conteúdo presente em nosso cotidiano, pois a cada escolha que devemos realizar, empregamos o Princípio Aditivo ou o Princípio Multiplicativo. De modo geral, esse conteúdo é ministrado com base no livro didático como material de apoio, ou seja, na maioria das vezes, os professores acabam utilizando somente esse recurso, o que nem sempre desperta o interesse do aluno. Outros recursos podem motivá-los, por exemplo, o uso de materiais manipuláveis e jogos que envolvam o raciocínio lógico. Essas estratégias podem tornar o conteúdo mais compreensível e agradável aos estudantes.

Durante a pesquisa foram desenvolvidas cinco atividades envolvendo o Princípio Aditivo e o Princípio Multiplicativo, todas abrangendo jogos e utilizando Materiais Manipuláveis. Porém, para esse trabalho, destacamos somente uma atividade: um jogo de cartas em que os alunos puderam manipular as mesmas, facilitando assim, as possibilidades de jogadas.

Durante a atividade, utilizamos a Metodologia de Ensino-Aprendizagem da Matemática através da Resolução de Problemas, conforme Onuchic (1999), aliada ao jogo de cartas, buscando uma resposta a nossa questão de pesquisa: Quais as contribuições que a metodologia de resolução de problemas, utilização de jogos e materiais manipuláveis podem propiciar para o ensino e aprendizagem do Princípio Aditivo e Princípio Multiplicativo?

Foram agentes participantes da pesquisa alunos do $3^{\circ}$ ano do Ensino Médio Técnico em Agropecuária do Instituto Federal de Educação, Ciência e Tecnologia Farroupilha - Campus Alegrete. Os resultados, bem como os procedimentos realizados durante a pesquisa, foram totalmente qualitativos e angariados por meio das observações registradas no diário de campo da professora, gravações em áudio e os registros escritos dos alunos.

\section{Aportes teóricos}

Apresentamos, primeiramente, um breve histórico sobre o surgimento da Análise Combinatória, o modo como pode ser trabalhada na Educação Básica seguindo as orientações dos Parâmetros Curriculares Nacionais. Posteriormente, descrevemos a importância da utilização dos Materiais Manipuláveis no âmbito educacional e, por último, descrevemos os passos da metodologia de ensino utilizada.

\section{Análise Combinatória}

Os primeiros estudos que referenciaram a Análise Combinatória foram encontrados nos livros de História da Matemática, de forma esparsa. Percebemos que, ao longo da história, a Análise Combinatória se estruturou por meio do estudo das probabilidades. De acordo com Morgado et al. (1991, p.6), “... o desenvolvimento da Análise Combinatória deve-se em grande parte à necessidade de resolver problemas de contagem originados na teoria das probabilidades". 
No Brasil, a Análise Combinatória tornou-se conteúdo escolar a partir do século XX, mais precisamente em 1931, com a reforma de Francisco Campos.

Atualmente,

Com a promulgação da Lei de Diretrizes e Bases, em 1961, os Estados passaram a ter autonomia para a elaboração dos seus programas. Mais tarde, em 1996, com a publicação da nova Lei de Diretrizes e Bases da Educação Nacional (Lei 9.394/96), essa autonomia foi repassada às escolas. A partir de então, os programas do ensino Médio passaram a ser regulamentados pelas Diretrizes Curriculares Nacionais, tendo como subsídios os Parâmetros Curriculares Nacionais e as Orientações Curriculares Nacionais. (FONSECA, 2012, p. 36).

Na Educação Básica, os problemas de contagem são apresentados como Princípio Fundamental da Contagem, Arranjos, Permutações e Combinações. Esses tópicos são desenvolvidos nos capítulos de Análise Combinatória nos livros didáticos.

Para esta pesquisa, utilizamos os conceitos de Princípio Aditivo, conhecido como técnica de somar ou contar, e o conceito de Princípio Fundamental da Contagem, também denominado Princípio Multiplicativo ou Princípio Fundamental da Enumeração.

Aprender a contar relacionando grupos, ou seja, conjuntos de certos objetos, é a maneira como as crianças aprendem a contar. Morgado (1991) afirma que "contar" é a primeira técnica matemática aprendida pelas crianças. Esse autor também pontua que enumerar os elementos de conjunto, de forma a determinar quantos são seus elementos, também é uma técnica de "contar".

Conforme o mesmo autor, o Princípio Multiplicativo e o Princípio Aditivo constituem as ferramentas básicas para resolver os problemas de contagem. Ele define o Princípio Fundamental da Enumeração, ou Princípio da Multiplicação, como: "Se uma decisão $d_{l}$ pode ser tomada de $x$ maneiras e se, uma vez tomada a decisão $d_{l}$, a decisão $d_{2}$

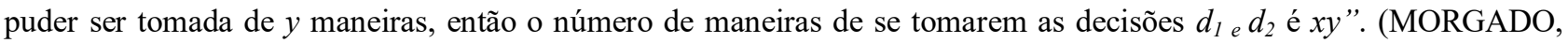
1991, p.18).

Com base na teoria apresentada pelos autores citados foram elaboradas as atividades que foram desenvolvidas junto aos alunos participantes da pesquisa.

\section{Materiais Manipuláveis e o uso dos Jogos no Âmbito Educacional}

Os Materiais Concretos ou Materiais Manipuláveis, para ensinar Matemática, são conhecidos desde o século XIX, porém não eram muito utilizados como auxiliares para a aprendizagem. Conforme Bordin (2011) a utilização destes materiais ajudam na compreensão dos conteúdos. No Brasil, a utilização desses materiais, no ensino da Matemática, irrompeu em meados de 1920, juntamente com o surgimento da tendência de ensino denominada empíricoativista. (BORDIN, 2011).

Segundo Reys (1971, apud MATOS e SERRAZINA, 1996, p. 193), Materiais Manipuláveis são “objetos ou coisas que o aluno é capaz de sentir, tocar, manipular e movimentar. Podem ser objetos reais que tem aplicação no dia a dia, ou podem ser objetos que são usados para representar uma ideia”.

Utilizar jogos, em sala de aula, é uma atividade atraente e divertida para os alunos. Segundo De Marco (2004), não é o jogo que ensina matemática, mas esse, quando intencionalmente definido, pode promover um contexto estimulador e desafiante para o pensamento, sendo um auxiliador didático na construção de conceitos matemáticos.

O uso de jogos e materiais manipuláveis ajuda na ilustração dos problemas, é desafiador tanto para o professor quanto para o aluno. Entretanto, é preciso orientar os alunos a buscarem os objetivos propostos em sala de 
aula, pois o professor deve ser o responsável pela criação e pela manutenção de um ambiente agradável, motivador e estimulante, que desperte a curiosidade do aluno para resolver problemas.

A utilização de jogos pode propiciar também o desenvolvimento de certas habilidades, por exemplo: raciocínio lógico para analisar as possibilidades na tomada de decisões, trabalhar em grupo, entre outras. Além disso, a utilização do jogo, em sala de aula, auxilia o aluno a desenvolver a interação social, a qual é indispensável para a compreensão de regras, o sentido de colaboração e o desenvolvimento social.

Segundo os PCN (BRASIL, 1998, p.47),

\begin{abstract}
Os jogos constituem uma forma interessante de propor problemas, pois permitem que estes sejam apresentados de modo atrativo e favorecem a criatividade na elaboração de estratégias de resolução e busca de soluções. Propiciam simulações vivas e imediatas, o que estimula o planejamento das ações, possibilitam a construção de uma atitude positiva perante os erros, uma vez que as situações sucedem-se rapidamente e podem ser corrigidas de forma natural, no decorrer da ação, sem deixar marcas negativas.
\end{abstract}

Desse modo, o uso de jogos, como auxiliadores na construção do conhecimento, pode ser visto como um processo cultural, inserido na realidade do aluno. Independente de idade, exercer as atividades lúdicas representa uma necessidade para as pessoas e promove o desenvolvimento do raciocínio matemático.

Na concepção de Carvalho (2009), o jogo pelo jogo não promove uma ampliação do campo conceitual. O professor deve torná-lo um auxiliador didático de seu planejamento, mantendo clareza nos objetivos a serem alcançados, bem como explicitando as competências e habilidades a serem atingidas.

\title{
A Metodologia de Resolução de Problemas
}

Como pioneiro em descrever um método de resolução de problemas, George Polya diz que resolver problemas é uma habilidade prática. Polya, aponta que “... o professor que deseja desenvolver nos estudantes a capacidade de resolver problemas deve colocar em suas mentes algum interesse por problemas, e proporcionar-lhes muitas oportunidades de imitar e de praticar" (POLYA, 2006, p.1). Ainda, de acordo com o mesmo autor, a ideia de resolver problemas, consiste em: “... encontrar um caminho previamente não conhecido, encontrar uma saída para uma situação difícil, para vencer um obstáculo, para alcançar um objetivo desejado que não pode ser imediatamente alcançado por meios adequados" (POLYA, 2006, p.5).

Em alguns relatos ele coloca que a Resolução de Problemas pode ser aplicada e desenvolvida em qualquer realidade do sujeito. A parte mais importante da formação matemática refere-se à maneira como se interpretam os problemas. O autor sugere que vale a pena agrupar indagações e sugestões típicas feitas pelos alunos, pois essas são de extrema importância para discussão posterior dos resultados.

O autor ressalta ainda que:

... se o aluno conseguir resolver o problema que lhe é apresentado, terá acrescentado alguma coisa à sua
capacidade de resolver problemas. Pela repetição da indagação, poderá chegar à ideia certa. Com tal sucesso, ele
descobrirá a maneira correta de utilizar a indagação e assim a terá realmente assimilado". (POLYA 2006, p.3).

Polya sugere quatro etapas a serem desenvolvidas para a resolução de problemas: compreender o problema; estabelecer um plano para a resolução do problema; executar o plano; e o retrospecto para examinar a solução encontrada.

O autor evidência que o papel do professor é muito importante no processo de Resolução de Problemas, já que a ele cabe “ajudar” o aluno. Porém, essa ajuda deve ser feita com muito cuidado. Ele deve responder às dúvidas dos alunos com perguntas que os façam pensar no melhor caminho a seguir. 
No Brasil, a partir da década de noventa, têm-se os trabalhos de Onuchic sobre Resolução de Problemas. De acordo com Allevato e Onuchic a metodologia de "Ensino-Aprendizagem de Matemática através da Resolução de Problemas", consiste no caminho de ensinar Matemática por intermédio da Resolução de Problemas e não apenas para ensinar a resolver problemas. (ALLEVATO; ONUCHIC, 2009).

As autoras destacam que a maioria (se não todos) os conceitos e procedimentos matemáticos podem ser melhor ensinados por meio da Resolução de Problemas. Segundo elas, não há dúvida de que ensinar por meio de resolução de problemas é difícil. As tarefas precisam ser planejadas ou selecionadas a cada dia, considerando a compreensão dos alunos e as necessidades do currículo. Todavia, ainda há razões de se fazer esforços ao utilizar essa metodologia de ensino-aprendizagem.

- A Resolução de Problemas coloca o foco da atenção dos alunos sobre ideias e sobre "dar sentido". Ao resolver problemas, os alunos necessitam refletir sobre as ideias que estão inerentes e/ ou ligadas ao problema;

- A Resolução de Problemas desenvolve o poder matemático;

- A Resolução de Problemas desenvolve a crença de que os alunos são capazes de fazer matemática e de que essa disciplina faz sentido;

- A Resolução de Problemas provê dados de avaliação contínua, que podem ser usados para tomar decisões instrucionais, ajudar os alunos a ter sucesso;

- A excitação de desenvolver a compreensão dos alunos, através de seu próprio raciocínio, vale todo o esforço e de fato, é divertido, também para os alunos. (ONUCHIC e ALLEVATO, 2012, p.243-244).

Allevato e Onuchic (2009) apresentam nove etapas a serem seguidas para a utilização dessa metodologia:

- Preparação do problema;

- Leitura individual;

- Leitura em conjunto;

- Resolução do problema;

- Observação e incentivo;

- Registro das resoluções na lousa;

- Plenária;

- Busca do consenso;

- Formalização do conteúdo. (ALLEVATO, ONUCHIC, 2009 p.7-8)

A opção pelo uso dessa metodologia pressupõe o professor como mediador da construção do conhecimento e o aluno como o agente construtor desse conhecimento.

\section{Metodologia da pesquisa}

A pesquisa realizada foi de cunho qualitativo. Para Lüdke e André (1986), uma pesquisa qualitativa tem "o ambiente natural como sua fonte direta de dados e o pesquisador como seu principal instrumento". Um dos aspectos importantes da pesquisa qualitativa é que ela permite um acompanhamento mais minucioso e detalhado durante o seu desenvolvimento. Algumas vantagens abordadas por este tipo de pesquisa são:

\footnotetext{
... poder descrever a complexidade de uma determinada hipótese ou problema, analisar a interação de certas variáveis, compreender e classificar processos dinâmicos experimentados por grupos sociais, apresentar contribuições no processo de mudança, criação ou formação de opiniões de determinado grupo e permitir em maior grau de profundidade, a interpretação das particularidades dos comportamentos ou atitudes dos indivíduos. (OLIVEIRA, 2002, p.117)
}

De acordo com D’Ambrósio (2004), o estudo qualitativo é um caminho para fugir do método de quantificar o aluno, uma vez que esse se preocupa com o contexto envolvido, com as pessoas e ideias, trazendo à tona falas e narrativas que antes permaneciam silenciosas.

Nessa pesquisa buscamos analisar as contribuições da metodologia de Resolução de Problemas e a utilização de materiais manipuláveis e jogos para o ensino e aprendizagem dos Princípios Aditivo e Multiplicativo do conteúdo de Análise Combinatória. 
Essa pesquisa foi desenvolvida em sala de aula, em uma turma com 28 alunos matriculados no $3^{\circ}$ ano do Ensino Médio Técnico em Agropecuária do Instituto Federal de Educação, Ciência e Tecnologia Farroupilha - Campus Alegrete, durante o segundo semestre de 2015. Os alunos foram distribuídos em oito grupos contendo três integrantes, e um grupo contendo quatro integrantes. Cada grupo recebeu uma lauda explicando a atividade a ser resolvida e foi disponibilizado, aos grupos, o material manipulável necessário para auxiliar nas resoluções.

A atividade descrita nesse trabalho ocorreu em três horas-aula, sendo que, durante as duas primeiras, realizamos as leituras e a resolução do problema. Em um segundo momento, se deu a discussão da atividade, por meio dos registros no quadro, plenária, consenso e formalização dos conceitos.

Os instrumentos de pesquisa que utilizamos foram: a) O Diário de Campo do Professor, que auxiliou nos registros das observações. Foram registradas todas as possíveis dúvidas, certezas e comentários feitos pelos alunos no decorrer do desenvolvimento e nas discussões sobre os objetivos propostos e as resoluções feitas pelos mesmos; b) Registro das Atividades, que foi realizado de duas formas: na primeira foi distribuída uma folha em branco onde os alunos puderam fazer seus apontamentos, descrever suas explicações e as estratégias utilizadas para a resolução da atividade; e a segunda forma de registro se deu por meio de gravação em áudio; c) Observação Participante, em que observamos todas as ações desenvolvidas em sala de aula e o comportamento dos alunos na busca por estratégias para as possibilidades de jogadas, em que as possibilidades de jogos, neste momento, se comportaram como os problemas a serem resolvidos.

Durante a realização da pesquisa, seguimos as seguintes etapas:

a) Leitura Individual e em Conjunto: nessa etapa os alunos, já dispostos em seus grupos, receberam uma folha com a atividade prevista, bem como o material manipulável solicitado pela atividade. Inicialmente, cada grupo realizou sua leitura e, posteriormente, a professora e os alunos fizeram uma leitura em conjunto;

b) Resolução do Problema: os alunos, em seus grupos, realizaram um trabalho cooperativo e colaborativo, tentando resolver os problemas, que muitas vezes foram discutidos entre seus pares e a professora, indagando as possibilidades de construções até que os alunos pudessem estabelecer conexões entre o problema, os materiais manipuláveis e as possibilidades de jogadas;

c) Estratégias de Resolução: perante o problema, os alunos construíram estratégias de resolução, anotando todas as possíveis informações já adquiridas durante as leituras e no decorrer da resolução das atividades, utilizando o material manipulável e o jogo envolvido;

d) Observação e Incentivo: durante essa etapa, a professora procurou desempenhar um papel de incentivadora e auxiliando os alunos a serem construtores de seus conhecimentos. Nessa etapa, foram feitas as anotações no Diário de Campo, observando a maneira como os alunos tentaram resolver os problemas, suas estratégias, suas dúvidas e suas certezas. Entretanto, a professora os ajudou, incentivando-os a resolverem as situaçõesproblema, desafiando-os quanto às suas capacidades intelectuais;

e) Registro das Atividades no Quadro: nessa etapa, os alunos foram convidados a registrar, no quadro, suas resoluções, independentemente de estarem certas ou erradas. A ideia era de que os diferentes processos de resolução fossem apresentados para que todos os alunos analisassem e discutissem as estratégias com o intuito de chegarem a um consenso;

f) Plenária: com as resoluções no quadro, foi aberta uma plenária, ou seja, uma discussão sobre os métodos de resolução utilizados pelos alunos e a professora sanou as dúvidas que ficaram durante o processo de resolução. 
Nessa etapa, a professora comportou-se como mediadora das discussões e, em alguns momentos, fez perguntas para auxiliar os alunos a chegarem à resolução mais adequada;

g) Busca do Consenso: após serem sanadas as dúvidas e analisadas as resoluções obtidas por cada um dos grupos, a professora buscou o consenso sobre o resultado para cada situação-problema;

h) Formalização do Conteúdo: nessa etapa, a professora formalizou os conceitos de Princípio Aditivo e Multiplicativo, organizando a estrutura em linguagem matemática, padronizando os conceitos, os princípios e os procedimentos construídos por meio da resolução dos problemas.

\section{Análise e discussões da atividade}

A atividade desenvolvida nesta pesquisa refere-se a um jogo conhecido e jogado pelos próprios participantes, com intuito de desenvolver a criticidade e criatividades dos alunos, despertando o interesse e a curiosidades dos mesmos.

Ao aplicar essa atividade, tínhamos como objetivo desenvolver o raciocínio lógico e combinatório dos alunos, explorando as estratégias a serem utilizadas durante as resoluções das possibilidades de jogadas, de modo que os estudantes aplicassem o Princípio Aditivo e Multiplicativo.

Para a resolução da tarefa, os grupos receberam uma lauda com as explicações sobre as retiradas de cartas do baralho e as possibilidades de jogadas, bem como um baralho para manuseio com o intuito de auxiliar os estudantes durante suas estratégias de resoluções.

O jogo a que nos referimos (Jogo de Truco) caracteriza-se por estabelecer jogadas de acordo com os naipes do baralho, sendo este um baralho espanhol contendo quatro naipes e 40 cartas. $O$ jogo de truco é muito conhecido na região dos sujeitos da pesquisa. Assim, os alunos têm por hábito jogá-lo em seus horários de intervalo. Cada pessoa senta-se ao lado de um adversário e as cartas são distribuídas uma a uma. Para a realização da atividade, consideramos a retirada de seis cartas e algumas nomenclaturas do próprio jogo, referente aos pares, ou trios, de cartas de mesmo naipe.

Ao distribuir as atividades, explicamos aos alunos as regras do jogo.

Professora: Como é de conhecimento de todos vocês, um baralho de truco é composto por 40 cartas, sendo essas divididas em 4 naipes (espada, bastos, ouros e copas). Cada naipe possui 10 cartas (Ás, 2, 3, 4, 5, 6,7, 10,11 e 12). Para a realização da atividade, utilizaremos o baralho de truco como auxiliador nas possibilidades de jogadas pré-estabelecidas, ou seja, as situações problemas.

Cada grupo, ao receber o baralho, deve retirar 6 cartas, em posição de jogo, ou seja, uma para cada um até que as duas pessoas tenham três cartas cada uma. As cartas devem ser distribuidas uma a uma. Por exemplo: a primeira para o primeiro jogador; a segunda para o segundo jogador, a terceira para o primeiro jogador e assim por diante.

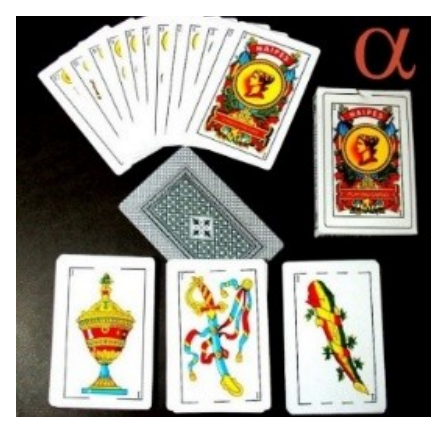

Figura 1 - um baralho de truco 
Dada as explicações iniciais, solicitamos aos alunos que resolvessem as situações problemas a seguir:

a) De quantas maneiras diferentes é possível distribuir essas cartas?

Para a resolução desta alternativa, os alunos deveriam dispor os jogadores, pois as cartas são dadas uma a uma a cada jogador, ou seja, o jogador um recebe a primeira carta, o jogador dois recebe a segunda, o jogador um recebe a terceira, o jogador dois recebe a quarta, o jogador um recebe a quinta e o jogador dois recebe a sexta carta. Dessa forma, aplicando o Princípio Multiplicativo, temos a seguinte disposição: 40 × 39 × 38 × 37 × 36 × 35 , totalizando 2.763.633.600 possibilidades de distribuição das cartas.

A professora indagou: Quantas possibilidades temos para distribuir a primeira carta? E a segunda carta? Os alunos discutiram em seus grupos as possibilidades.

O grupo 4 apresentou uma resolução, considerando que, para cada carta distribuída, existiam 40 possibilidades, ou seja, não consideraram que uma carta já havia sido dada e que, então, restavam 39 cartas para a segunda distribuição. A resolução pode ser vista na Figura 2, a seguir:

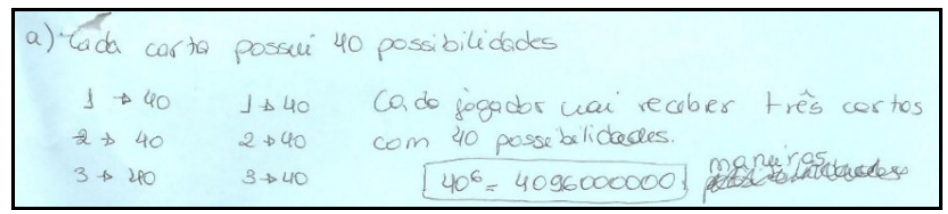

Figura 2: Resolução apresentada pelo grupo 4

Fonte: dados da pesquisa

Os grupos 2 e 5 distribuíram corretamente as cartas, considerando os dois jogadores, esclarecendo os esquemas de recebimento das cartas. Porém, consideraram dois grupos distintos como mostra a Figura 3.

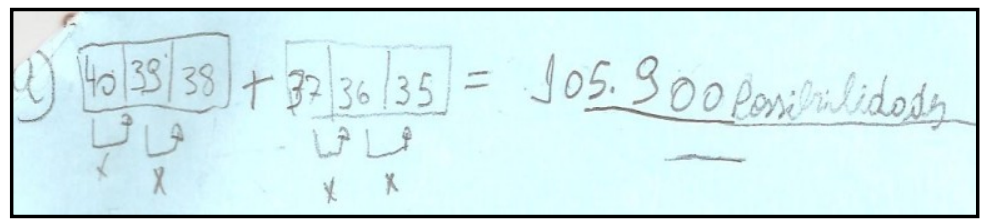

Figura 3: Resolução apresentada pelo grupo2

Fonte: dados da pesquisa

Os grupos 1, 3, 6, 7 e 9 conseguiram interpretar corretamente a atividade, estabelecendo esquemas para a resolução da alternativa, o que facilitou a percepção de quando aplicar o Princípio Aditivo e o Multiplicativo. Os alunos separaram os dois princípios, percebendo a diferença entre eles e quando aplicá-los, individualmente e em conjunto, conforme explicitado na Figura 4:

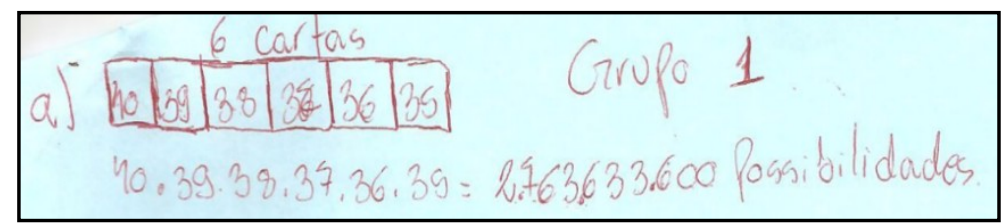

Figura 4: Resolução apresentada pelo grupo 1

Fonte: dados da pesquisa

b) Quantas são as possibilidades de um dos jogadores sair com três das cartas mais altas do baralho? (Ás de espada, Ás de bastos Sete de espadas e Sete de ouros).

Como são quatro cartas mais altas, considera-se que, para a primeira posição, há quatro possibilidades; para a segunda, são três, visto que uma já saiu e, para terceira, são duas possibilidades, porque as outras duas já saíram. Portanto, aplicando o Princípio Multiplicativo, é possível encontrar 4 × 3 × $2=24$ possibilidades. 
Durante a apresentação das resoluções dessa atividade, percebemos que os grupos 1 e 7 consideraram todas as cartas para a distribuição, não interpretando corretamente o que pedia na alternativa, ou seja, não consideraram somente as 4 maiores. Essa resolução é apresentada na Figura 5:

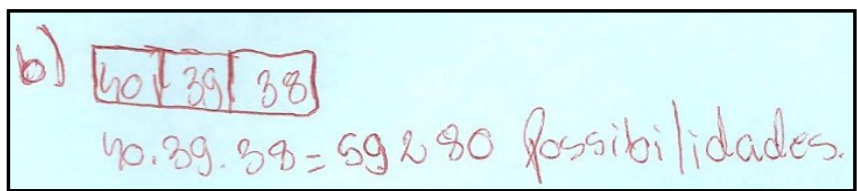

Figura 5 - Resolução apresentada pelo grupo 1

Fonte: dados da pesquisa

Observamos que esse grupo não compreendeu o problema e não conseguiu esquematizar uma solução. Os alunos não conseguiram distinguir esta questão da questão anterior.

Os grupos 2, 5 e 9 conseguiram interpretar a questão, separando as quatro cartas maiores do baralho e esquematizando possibilidades conforme pode ser visualizado na Figura 6.

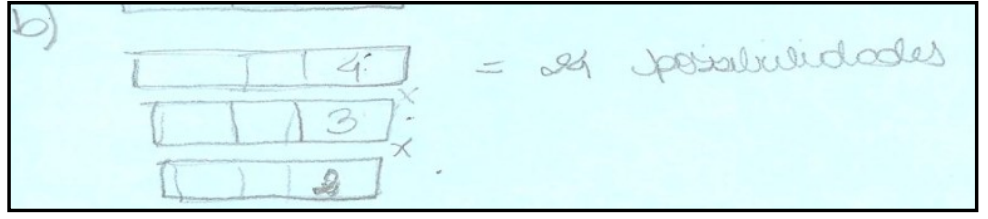

Figura 6- Resolução apresentada pelo grupo 9

Fonte: dados da pesquisa

O grupo 2 considerou somente três cartas e não as quatro, como mostra a Figura 7.

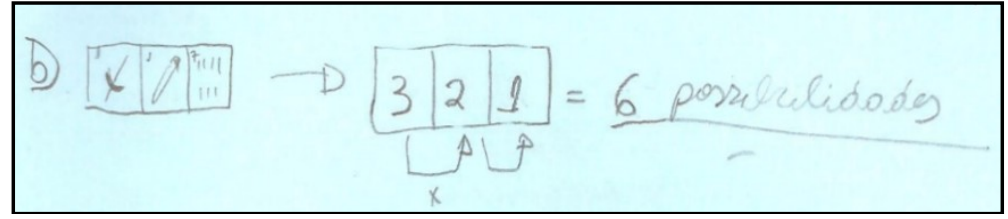

Figura 7- Resolução apresentada pelo grupo 2

Fonte: dados da pesquisa

c) De quantas maneiras dois jogadores podem ter uma flor (para possuir uma flor, o jogador deverá conter na mão três cartas do mesmo naipe), porém, cada um dos jogadores com uma flor de naipes diferentes?

Nesta alternativa, a primeira carta dada ao jogador um pode ser qualquer uma das 40 cartas do baralho. É essa que fixará o naipe. Sobrarão 30 cartas para a primeira opção do jogador dois, que também fixará o naipe, não sendo igual ao do primeiro jogador.

Com os naipes fixados, o jogador um poderá receber, na segunda rodada, somente umas das 9 cartas restantes do naipe fixado e, na terceira jogada, 8 cartas. $\mathrm{O}$ mesmo acontece com o jogador dois, ou seja, na segunda jogada, ele poderá receber 9 cartas e, na terceira, 8 cartas.

Para cada jogador, é preciso aplicar o Princípio Multiplicativo (jogador um: 40 x 9 × $8=2880$; jogador dois: $30 \times 9 \times 8$ =2160). Como os jogadores pertencem a grupos distintos, realiza-se a soma das possíveis jogadas de cada um, isto é, o Princípio Aditivo. Logo, o total de possibilidades é: $2880+2160=5040$ possíveis flores de naipes diferentes aos dois jogadores. 
O grupo 1 separou os naipes e encontrou as possibilidades de sair flor em cada um dos naipes, conforme mostra a Figura 8. Nesse caso, foi aplicado o Princípio Multiplicativo e o Princípio Aditivo, quando foram somadas as possibilidades dos naipes.

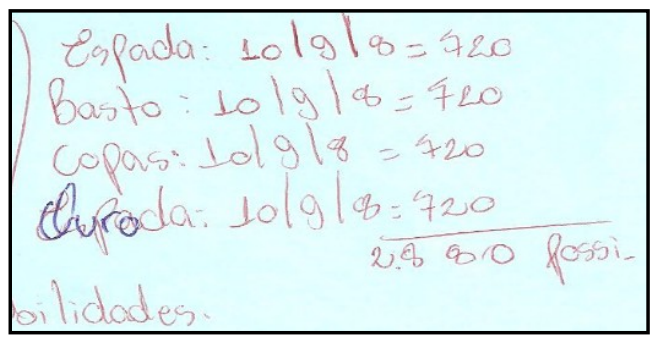

Figura 8: Resolução apresentada pelo grupo 1

Fonte: dados da pesquisa

O grupo 7 conseguiu estabelecer que, para a primeira distribuição das cartas, havia 40 possibilidades e que, para a segunda, havia 30 possibilidades para distribuírem as próximas cartas. Não fixaram o naipe, ou seja, não levaram em consideração que havia 10 cartas em cada naipe e que a primeira carta distribuída fixaria um dos naipes. Por outro lado, desenvolveram o Princípio Multiplicativo para cada jogador e o princípio Aditivo entre os jogadores. Tal resolução é apresentada na Figura 9:

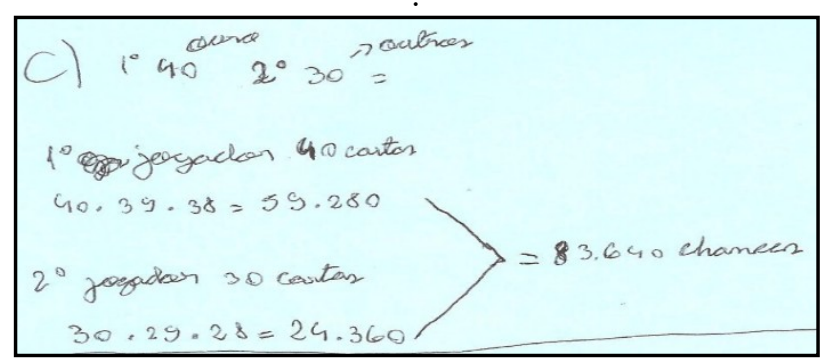

Figura 9: Resolução apresentada pelo grupo 7 Fonte: dados da pesquisa

O grupo 6 distribuiu cartas somente para o jogador um, conseguindo diagnosticar o Princípio Multiplicativo, não realizando a adição entre os dois jogadores porque disponibilizou cartas somente para um jogador, o que é confirmado na Figura 10, a seguir:

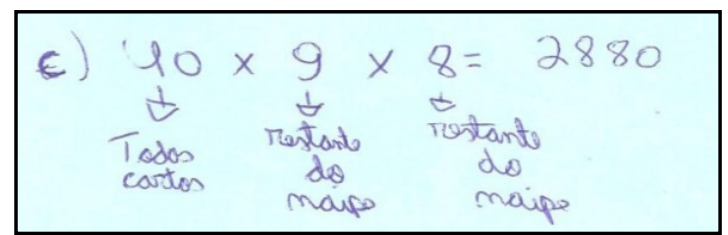

Figura 10: Resolução apresentada pelo grupo 6

Fonte: dados da pesquisa

Os grupos 2, 3, 5 e 9 conseguiram estabelecer as reflexões sobre o pensamento combinatório, esquematizando o processo de distribuição das cartas e aplicando o Princípio Multiplicativo para as possibilidades de cada jogador e depois o Princípio Aditivo. Os alunos desse grupo também juntaram as possibilidades dos dois jogadores. A resolução do grupo 3 é apresentada na Figura 11: 


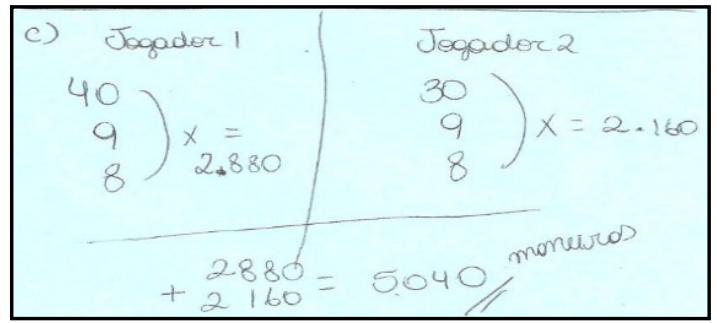

Figura 11: Resolução apresentada pelo grupo 3

Fonte: dados da pesquisa

Nesta situação problema observamos que os alunos apresentaram dificuldades. Pois os conceitos referentes aos Princípios Aditivo e Multiplicativo ainda não estavam bem sedimentados.

d) De quantas maneiras pode-se ter uma flor para cada jogador de modo que essa flor seja do mesmo naipe para os dois jogadores?

Para que os dois jogadores tenham flores de mesmo naipe, a primeira opção para o jogador um, continua sendo o total de cartas (40), visto que essa carta irá fixar o naipe para as outras cinco cartas restantes a serem distribuídas.

Na primeira rodada, o primeiro jogador tem 40 possibilidades; na segunda jogada, 8 possibilidades; e na terceira jogada, 6 possibilidades. Já o jogador dois, tem na primeira rodada 9 possibilidades, pois o naipe já foi fixado quando distribuída a primeira carta ao jogador um; na segunda rodada, o jogador dois terá 7 possibilidades de cartas; e, na terceira rodada, 5 possibilidades.

Nessa atividade houve várias respostas distintas, pois os grupos conseguiram identificar a utilização do Princípio Multiplicativo, mas, em alguns momentos, não conseguiram separar as cartas decorrentes para cada jogador em seus naipes corretamente.

Somente dois grupos não conseguiram aplicar o Princípio Aditivo.

Todos os outros seis grupos realizaram o Princípio Multiplicativo para cada jogador e o Aditivo para a soma das possibilidades dos dois jogadores. O raciocínio utilizado pelos grupos é mostrado nas Figuras 12 e 13, a seguir.

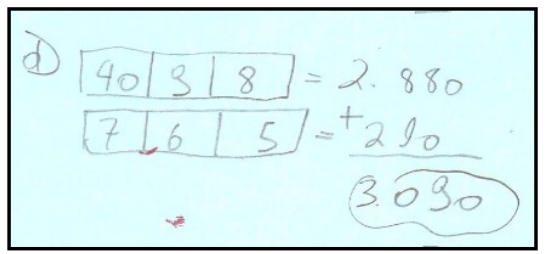

Figura 12: Resolução apresentada pelo grupo 2

Fonte: dados da pesquisa

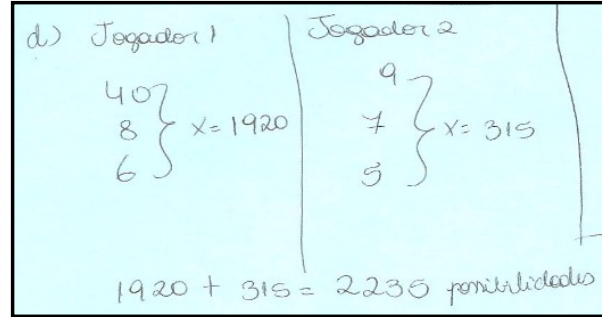

Figura 13: Resolução apresentada pelo grupo 3

Fonte: dados da pesquisa

e) Quantas são as possibilidades para que os dois jogadores tenham um imbido, de maneira que as cartas do mesmo naipe para o jogador um sejam cartas de naipes diferentes das cartas do jogador dois? (o imbido é composto de duas cartas de mesmo naipe). 
Para o aluno utilizar o mesmo pensamento das jogadas anteriores é necessário verificar que o jogador um, na primeira rodada, terá 40 possibilidades de receber suas cartas que fixa o naipe para o imbido. Já para a segunda rodada, ele terá disponível 9 cartas, pois essa deve ser de mesmo naipe que a primeira, porém, para a terceira rodada, ele poderá receber qualquer carta que não seja do naipe fixado, sobrando 30 cartas para essa rodada. Assim, o jogador um terá $40 \mathrm{x}$ $9 \times 30=10800$ possibilidades:

O jogador dois terá 30 possibilidades de cartas para receber na primeira rodada porque não poderá receber carta do naipe do jogador um. Na segunda rodada, esse jogador poderá receber 9 cartas. Entretanto, na terceira rodada, poderá receber qualquer carta que não seja do naipe das primeiras, inclusive uma carta do naipe do imbido do jogador um. Logo, o jogador dois tem 30 × 9 × $30=8100$ possibilidades de receber essas cartas.

Utilizando os Princípios Multiplicativo e Aditivo têm-se $10800+8100=18900$ possibilidades de os dois jogadores saírem com um imbido cada um de naipes diferentes.

O Grupo 4 apresentou a seguinte resolução: "5 pares $x 3$ naipes $=15 \times 10$ cartas $=150 \times 4$ naipes $=600$ possibilidades”. Para que chegassem a essa solução, houve um desenvolvimento do pensamento combinatório, utilizando o Princípio Multiplicativo, mas não houve nenhuma aplicação do Princípio Aditivo, isto é, os alunos consideraram as possibilidades de encontrarem duas cartas de mesmo naipe e não as possibilidades de cartas para cada jogador.

Os alunos do Grupo 1 representaram a distribuição de duas cartas de mesmo naipe, em cada um dos naipes, utilizando o Princípio Multiplicativo e, portanto, somando as possibilidades de cada naipe, aplicando o Princípio Aditivo. Isso é visualizado na Figura 14 que segue:

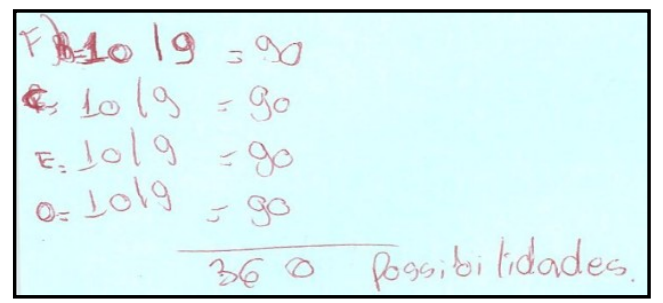

Figura 14: Resolução apresentada pelo grupo 1

Fonte: dados da pesquisa

Os alunos dos Grupos 2 e 7 conseguiram esquematizar a ideia da distribuição das cartas para os dois jogadores aplicando o Princípio Multiplicativo para cada jogador e, o Princípio Aditivo para encontrar as possibilidades dos dois jogadores. Podemos observar a resolução desses grupos nas Figuras 15 e 16, a seguir.

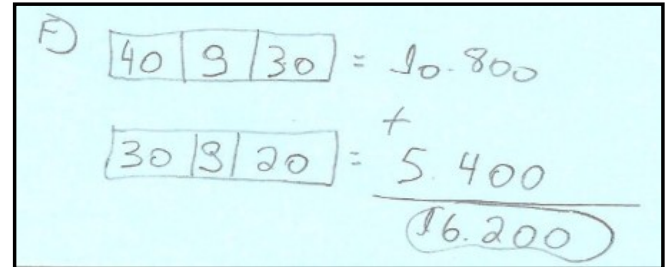

Figuras 15: Resolução apresentada pelo grupo 2 Fonte: dados da pesquisa

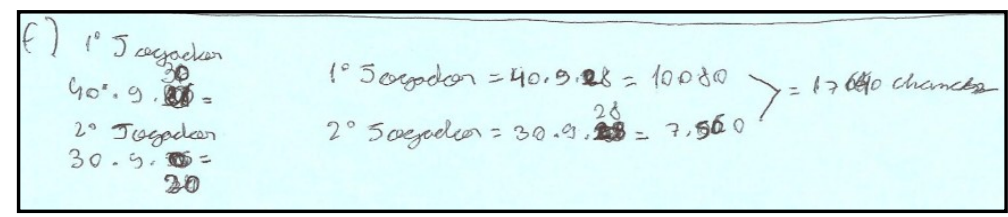

Figura 16: Resolução apresentada pelo grupo 7

Fonte: dados da pesquisa 
Os alunos do Grupo 6 esquematizaram a distribuição de cartas somente para um jogador, de acordo com a Figura 17:

$$
\text { A) } 10 \times 9 \times 30=2700 \times 3=8100 \text { porsubilibutes }
$$

Figura 17: Resolução apresentada pelo grupo 6

Fonte: dados da pesquisa

A resolução correta apresentada foi realizada somente por um dos grupos, o Grupo 3. Essa pode ser observada na Figura 18, a seguir:

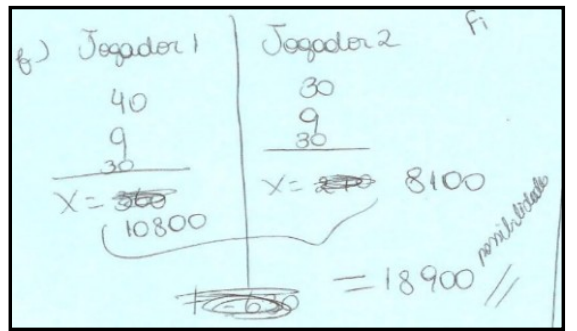

Figura 18: Resolução apresentada pelo grupo 3

Fonte: dados da pesquisa

Durante a plenária dessas atividades, os alunos apresentaram um comportamento agitado, pois como este jogo é muito comum eles, acreditavam que estavam corretos em todas as questões perguntadas.

Entretanto, quando começaram a escrever suas resoluções na lousa puderam ver que, em alguns momentos, não houve concordância geral entre todos os colegas. Porém, foi muito interessante a plenária dessas atividades, pois os alunos participaram integralmente e compreenderam a diferença entre o Princípio Multiplicativo e o Princípio Aditivo e como aplicar corretamente esses dois princípios o que facilitou a formalização dos conceitos.

Acreditamos que tal atividade serviu para um diagnóstico do desenvolvimento do conteúdo a ser estudado e, aos poucos, os alunos, em seus grupos, foram se aproximando mais e criando grupos de estudo inclusive em outras disciplinas.

\section{Consideracões finais}

Nesta pesquisa nos propomos o desafio de trabalhar com a metodologia de Resolução de Problemas, para tornar as aulas de Matemática mais prazerosas e motivadoras ao desenvolver o conteúdo de Análise Combinatória. Observamos que a utilização do jogo de truco foi uma boa estratégia para buscar as possibilidades de jogadas e facilitou a compreensão e interpretação das situações problematizadas.

No decorrer da realização das atividades observamos que os grupos apresentaram algumas dificuldades em trabalhar seguindo os passos dessa metodologia.

Onuchic enfatiza que:

O problema é olhado como um elemento que pode disparar um processo de construção do conhecimento. Sob esse enfoque problemas são propostos ou formulados de modo a contribuir para a formação dos conceitos antes mesmo de sua apresentação e linguagem formal. O foco está na ação por parte do aluno. (ONUCHIC, 1999, p.207). 
Podemos inferir que a metodologia de ensino utilizada neste trabalho, aliada à utilização do jogo e a manipulação das cartas para efetuar as jogadas, contribuíram para tornar as aulas mais interessantes, dinâmicas e significativas para os alunos, que puderam explorar e desenvolver um raciocínio combinatório.

Todos os grupos relataram que, durante o início das atividades, sentiram dificuldade, pois estavam acostumados com o método tradicional de ensino, em que, primeiro, o professor explicaria e depois eles partiriam para a resolução de problemas, de acordo com a exposição feita pelo grupo 03, relatada na figura que segue:

3

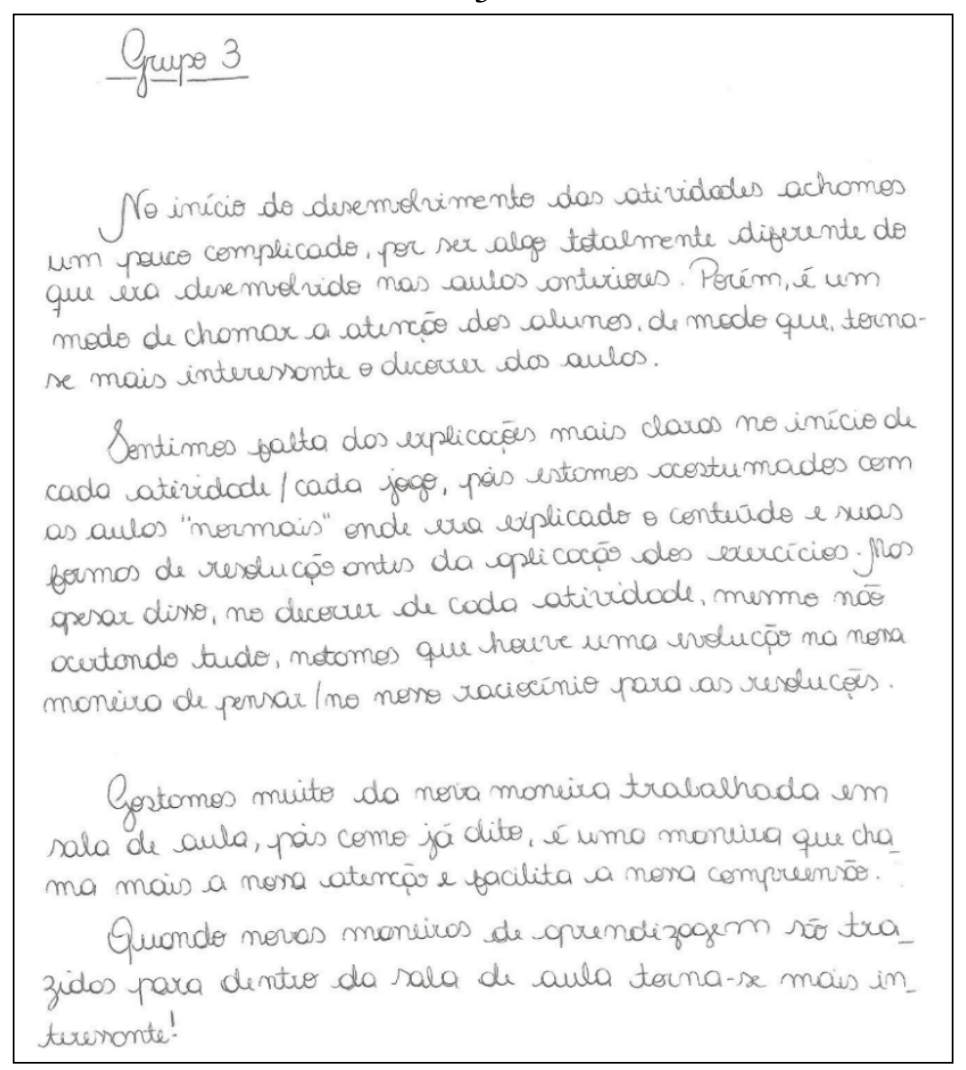

Figura 19: Relato final apresentado pelo grupo Fonte: dados da pesquisa

Esse relato, apresentado pelo grupo 3, pode explicitar a interpretação dos alunos quanto às atividades desenvolvidas, como se sentiram e de que maneira foram evoluindo.

A experiência relatada permitiu inferir que a metodologia da resolução de problemas permitiu detectar as dificuldades dos alunos na interpretação dos problemas e no traçado de estratégias para obter uma solução. Observouse, também, que essa metodologia aliada à utilização de materiais manipuláveis favoreceu os alunos na tomada de decisões e no delineamento de estratégias de solução.

\section{Referências}

ALFARO, Cristian. Las Ideas de Pólya en la Resolución de Problemas. Cuadernos de Investigación y Formación Matemática, Escuela de Matemática, Universidad Nacional José Romilio Loría. Costa Rica, 2006, año 1, nº1.

ALlEVATO, N. S. G; ONUCHIC, L. R. Trabalhando volume de cilindros através da resolução de problemas. Educação Matemática em Revista - RS, v.10, n.1, p. 95-103, 2009. 
ALLEVATO, Norma Suely Gomes; ONUCHIC, Loudes de La Rosa. Novas reflexões sobre o ensino-aprendizagem de Matemática através da resolução de problemas. In: BICUDO, M. A. V.; BORBA, B. C. de (org.) Educação Matemática: pesquisa em movimento. São Paulo: Editora Cortez, 2012. p. $232-252$

BICUDO, M. A. V.; BORBA, M. de C. (Orgs.). Educação Matemática: pesquisa em movimento. 4ed. São Paulo: Cortez, 2012.

BORDIN, Laura Moreira. Os Materiais Manipuláveis e os Jogos Pedagógicos como Facilitadores do Processo de Ensino e Aprendizagem das Operações com Números Inteiros. 2011. 102 f. Dissertação de Mestrado (Mestrado profissionalizante em Ensino de Física e de Matemática) - Centro Universitário Franciscano, Santa Maria, RS, 2011.

BRASIL, Ministério da Educação - Secretária de Educação Fundamental - PCN Parâmetros Curriculares Nacionais. Brasília: MEC/SEF, 1998.

CARVALHO, Gustavo Quevedo. USO DE JOGOS NA RESOLUÇÃO DE PROBLEMAS DE CONTAGEM: Um Estudo de Caso em uma turma de $\mathbf{8}^{\mathbf{0}}$ ano do Colégio Militar de Porto Alegre. 2009. 195 f. Dissertação de Mestrado (Ensino de Matemática) Programa de Pós - Graduação de Ensino de Matemática, Universidade Federal do Rio Grande do Sul, Porto Alegre, RS, 2009.

D’AMBROSIO, U. Prefácio. In: Pesquisa qualitativa em educação matemática. Belo Horizonte: Autêntica, 2004.

DASSIE, B. A. Euclides Roxo e a constituição da Educação Matemática no Brasil. Tese (Doutorado em Educação) Programa de Pós - Graduação, PUC, Rio de Janeiro, 2008.

DE MARCO, Fabiana Fiorezi. Estudos dos Processos de Resolução de Problemas Mediante a Construção de Jogos computacionais de Matemática no Ensino Fundamental. SP: [s.n], 2004. Dissertação de Mestrado (Mestrado), Universidade Estadual de Campinas, Faculdade de Educação.

FONSECA, Jussara Aparecida da. Análise Combinatória na Educação de Jovens e Adultos: uma proposta de ensino a partir da resolução de problemas. 2012. 178 f. Dissertação de Mestrado (Educação Matemática) Programa de Pós Graduação de Ensino de Matemática, Universidade Federal do Rio Grande do Sul, Porto Alegre, RS, 2012.

LÜDKE, M., ANDRÉ, M. E. D. A. Pesquisas em educação: abordagens qualitativas. São Paulo: EPU, 1986.

MATOS, J. M.; SERRAZINA, M. de L. Didática da Matemática. Universidade Aberta: Lisboa, 1996.

MORGADO, A. C. et al. Análise Combinatória e Probabilidade. Rio de Janeiro: SBM, 1991.

OLIVEIRA, L. Tratamento de metodologia científica. São Paulo: Pioneira, 2002.

ONUCHIC, L. Ensino Aprendizagem de matemática através da Resolução de Problemas. In: BICUDO, M. A. V. (Org). Pesquisa em Educação Matemática: concepções e perspectiva. São Paulo: Ed. UNESP, 1999. p. 199-218.

POLYA, George. A arte de resolver problemas. Rio de Janeiro, Interciência. 2006. 